\title{
Tingkat Kepuasan Mahasiswa DIII Keperawatan dalam Pembelajaran Klinik
}

\author{
Upik Rahmi $^{*}$, Suci Tuty Putri ${ }^{2}$, Dian Maiszha ${ }^{3}$
}

${ }^{1,2}$ Program Studi DIII Keperawatan, Universitas Pendidikan Indonesia, Bandung, Indonesia

${ }^{3}$ Mahasiswa Program Studi DIII Keperawatan, Universitas Pendidikan Indonesia, Bandung, Indonesia

*Email korespondensi : upikrahmi@upi.edu

\section{ARTICLE INFO \\ HOW TO CITED: \\ Rahmi, U., Putri, S.T., and Maiszha, D. (2019). Tingkat Kepuasan Mahasiswa DIII Keperawatan dalam Pembela- jaran Klinik. Jurrnal Pendidi- kan Keperawatan Indonesia 5(2), p. 184-190}

DOI:

10.17509/jpki.v5i2.18076

ARTICLE HISTORY:

\section{Accepted}

November 11, 2019

Revised

December 30, 2019

Published

December 31, 2019

\begin{abstract}
A B S T R A K
Dalam dekade terakhir berbagai kajian dilakukan untuk menemukan metode pembelajaran terbaik antara preceptor dan mahasiswa dalam pembelajaran klinik. Hal ini bermakna bahwa metode pembelajaran yang tepat dapat meningkatkan pencapaian kompetensi mahasiswa dan akan berpengaruh terhadap tingkat kepuasan mahasiswa. Salah satu metode pembelajaran klinik yang sering diterapkan dalam pembelajaran klinik adalah metode Preceptorship, namun belum diketahui bagaimana kepuasaan mahasiswa terhdap metode tersebut. Tujuan penelitian ini adalah untuk mengetahui tingkat kepuasaan mahasiswa DIII Keperawatan dalam pembelajaran klinik. Desain penelitian adalah deskriptif kuantitatif. Instrumen menggunakan kuesioner yang disusun berdasarkan teori Service Quality (ServQual). Jumlah sampel adalah 93 mahasiswa, dengan teknik Purposive random sampling. Hasil penelitian menunjukan tingkat kepuasan mahasiswa adalah 49 responden $(52,7 \%)$ puas dan 44 responden $(47,3 \%)$ menyatakan tidak puas. Pada dimensi tangible 54,8\% menyatakan puas, dimensi reliability $62,4 \%$ menyatakan puas, dimensi responsiveness $66,7 \%$ menyatakan puas, dimensi assurance $74,2 \%$ puas, dan dimensi emphaty $80,6 \%$ menyatakan puas. Kepuasan mahasiswa behubungan dengan sikap, kesungguhan mereka saat menjalankan profesi mereka. Di harapkan pihak institusi pendidikan dan rumah sakit dapat mengembangkan berbagai metode pembelajaran yang lebih memperhatikan berbagai dimensi dalam kepuasaan pembelajaran klinik.
\end{abstract}

Kata Kunci : pendidikan klinik, preseptorship, mahasiswa keperawatan

\section{$A B S T R A C T$}

In the last decade, various studies have been carried out to find the best learning methods between preceptors and students in clinical learning. It means that the right learning method can increase the achievement of student competencies and will affect the level of student satisfaction. One of the clinical learning methods that are often applied in clinical learning is the Preceptorship method, but it is not yet known how student satisfaction with that method. The purpose of this study was to determine the level of satisfaction of Nursing DIII students in clinical learning. The research design is quantitative descriptive. The instrument uses a questionnaire prepared based on Service Quality theory. The number of samples was 93 students, using a purposive random sampling technique. The results showed the level of student satisfaction was 49 respondents (52.7\%) satisfied and 44 respondents (47.3\%) expressed dissatisfaction. On tangible dimension $54.8 \%$ expressed satisfaction, reliability dimension $62.4 \%$ expressed satisfaction, responsiveness dimension $66.7 \%$ expressed satisfaction, assurance dimension $74.2 \%$ satisfied, and empathy dimension $80.6 \%$ expressed satisfaction. Student satisfaction is related to their attitude, sincerity when carrying out their profession. It is hoped that educational institutions and hospitals can develop various learning methods that pay more attention to various dimensions in clinical learning satisfaction. 
Rahmi, U., Putri, S.T., and Maiszha, D.| Tingkat Kepuasan Mahasiswa DIII Keperawatan dalam Pembelajaran Klinik.

Keywords: clinical learning, level of satisfaction, Nursing student Diploma, preceptorship

\section{PENDAHULUAN}

Pembelajaran klinik sangat menentukan kualitas capaian pembelajaran mahasiswa keperawatan dimana pengetahuan dan keterampilan klinis merupakan hal mendasar dalam pendidikan keperawatan. Beberapa negara telah memfokuskan kajian pendidikan dalam masalah pendidikan klinik, untuk mendapatkan metode pembelajaran yang tepat. Pada tahun 2012, Asosiasi Canada School of Nursing (CASN) menerbitkan Nurse Practitioner Education : Kerangka Kerja Nasional Prinsip-Prinsip Panduan \& Komponen-Komponen Esensial. Salah satu bagiannya adalah memusatkan perhatian pada isu-isu terkait dengan preceptorship. (Roberts, Wheeler, Tyler, \& Padden, 2017). Di Inggris, Health Education England membentuk RePAIR, yang merupakan kelompok kerja fokus pada pendidikan siswa keperawatan, bidan dan fisioterapi. Telah menyoroti betapa pentingnya model preceptorship, mereka menyimpulkan bahwa komitmen organisasi sangat penting dan menguraikan persyaratan untuk mendukung keberhasilan model preceptorship, peran dosen, dan siswa serta melakukan. tinjauan program preceptorship memeriksa preceptorship (Health Education England, 2017) Odelius, Traynor, Mehigan, Wasike, \& Caldwell, 2017)

Pendidikan Diploma keperawatan di Indonesia menghasilkan lulusan perawat vokasional yang memiliki sikap dan kemampuan melalui penerapan kurikulum dengan berbagai bentuk pengalaman belajar, meliputi pengalaman belajar dikelas, laboratorium, klinik dan lapangan dengan fasilitas belajar yang menunjang tercapainya tujuan pembelajaran (AIPVIKI, 2015). Pembelajaran klinik memiliki keunggulan yang berfokus pada masalah nyata sehingga dapat memotivasi mahasiswa untuk berpartispasi aktif dalam pencapaian kompetensi(Nursalam \& Efendi, 2008). Metode bimbingan praktik klinik keperawatan yang saat ini sering digunakan adalah Metode Mentorship dan Preceptorship dengan didukung oleh manajemen dapat meningkatkan kemampuan dan pengetahuan mentor dan preseptor dalam memberikan asuhan keperawatan. Mentor dan preseptor memiliki peran besar dalam metode ini karena dapat membantu siswa dalam proses transisi dan integrasi ke dalam setting klinis dan area kerja. Mereka juga mendukung siswa keperawatan untuk mencapai kompetensi dan kepercayaan diri, serta terlibat dalam kehidupan professional. (Asmara, 2012)

Health Education England (HEE) (2017), menerbitkan standar preceptorship untuk mengklarifikasi persyaratan preseptor sebagai bagian dari Shape of Caring Review. Penelitian Odelius et al., (2017) menunjukkan bahwa mayoritas preceptee (mahasiswa) mendapatkan manfaat dari peningkatan kompetensi dan kepercayaan diri melalui program preceptorship. Minoritas preceptee merasa kurang berguna baik karena mereka berada di area spesialis atau karena hubungan yang buruk dengan pembimbing mereka. Penelitian lain di Indonesia oleh Windyastuti, Kristina, \& Santoso, (2016), Mukarromah dan Agustin, 2015 juga menunjukkan Preceptorship sangat membantu meningkatkan keterampilan calon perawat baru dalam mempersiapkan mereka memasuki dunia kerja dengan aman, adanya hubungan preceptor dengan self efficacy, serta metode ini dapat meningkatkan keterampilan mahasiswa.

Kepuasaan pelanggan (mahasiswa) merupakan evaluasi spesisfik terhadap keseluruhan pelayanan yang diberikan pemberi jasa (preseptor), sehingga kepuasaan mahasiswa menjadi gambaran keberhasilan proses pembelajaran klinik. Kotler (2003) menyatakan kepuasaan merupakan perasaan senang ataupun kecewa seseorang yang berasal dari perbandingan antara kesannya terhadap kinerja (atau hasil) suatu produk dan harapanharapannya. Apabila kinerja melebihi harapan, konsumen akan merasakan sangat puas. Ketika 
konsumen merasakan ketidakpuasan, konsumen akan enggan untuk menggunakan lagi jasa tadi. Kepuasan pelanggan terutama dibidang jasa menjadi keharusan agar perusahaan tetap sukses. Keunggulan suatu jasa tergantung pada keunikan serta kualitas yang diperlihatkan oleh jasa tersebut. Persepsi pelanggan terhadap kualitas pelayanan merupakan penilaian menyeluruh atas keunggulan suatu jasa.

Zeithaml, dan Berry(1994) dalam serangkaian penelitian menunjukkan bahwa perbedaan antara harapan konsumen mengenai kinerja dari perusahaan dan penilaian konsumen mengenai kinerja aktual memberikan suatu persepsi konsumen atas kualitas jasa. Dalam konteks pengukuran variabel kualitas pelayanan mereka mengidentifikasikan lima dimensi ukuran kualitas layanan yaitu reliability (keandalan), responsiveness (daya tanggap), assurance (jaminan), tangible (bukti langsung), dan empathy (empati). Pengukuran semacam ini dikenal sebagai model service quality (ServQual) (Zeithaml \& Berry, 1994).

Dimensi dalam kepuasaan model ServQual) terdiri dari 1) Bukti langsung (tangible); meliputi fasilitas fisik, perlengkapan, pegawai, dan sarana komunikasi 2) Keandalan (reliability); yakni kemampuan memberikan pelayanan yang dijanjikan dengan segera, akurat, dan memuaskan 3) Daya tanggap (responsiveness); yaitu keinginan para staf untuk membantu para pelanggan dan memberikan pelayanan dengan tanggap 4) Jaminan (assurance); mencakup pengetahuan, kemampuan, kesopanan, dan sifat dapat dipercaya yang dimiliki para staf, bebas dari bahaya, risiko, atau keragu-raguan 5) Empati (empathy); meliputi kemudahan dalam melakukan hubungan, komunikasi yang baik, perhatian pribadi, dan memahami kebutuhan para pelanggan (Zeithaml \& Berry, 1994).

Seorang pembimbing klinik hendaknya memahami dan memiliki kompetensi sebagai seorang preseptor dan mentor. Metode preseptorhip memberikan perhatian bimbingan kepada mahasiswa dalam masa transisi dari dunia akademik ke lingkungan klinik. Metode preseptorship dilakukan dengan 3 tahapan Darmawan (2012) antara lain awal, intermediate dan tahap akhir. Dimana preseptor mencari tahu tentang kebutuhan preseptee dalam bimbingan, membantu preseptee menentukan tujuan bimbingan yang ingin dicapai, menentukan topik diskusi yang sesuai, mengevaluasi dan memberikan feed back selama interaksi.

Berdasarkan uraian di atas penelitian ini bertujuan untuk mengetahui tingkat kepuasaan mahasiswa D III Keperawatan dalam pembelajaran klinik yang menggunakan metode preceptorship.

\section{METODE}

Desain penelitian yang digunakan dalam penelitian ini adalah deskriptif kuantitatif, dimana peneliti hanya ingin mengetahui gambaran kepuasaan mahasiswa terhadap pembelajaran klinik yang menerapkan metode preseptorship.

Populasi adalah mahasiswa DIII keperawatan semester enam salah satu Politeknik Kesehatan di kota Bandung yang telah menerapkan metode Preceptorship secara optimal. Jumlah populasi 120 responden, dengan jumlah sampel adalah 93 mahasiswa, pengambilan sampel dengan teknik Purposive sampling, dimana peneliti menetapkan beberapa Kriteria inklusi yaitu; responden baru menjalani praktik klinik (Praktek Belajar Lapangan) dengan metode Preceptorship. Kriteria eksklusi; Responden tidak lulus dalam praktik belajar lapangan (PBL) dengan metode Preceptorship.

Instrumen penelitian menggunakan kuesioner yang peneliti kembangkan berdasarkan teori ServQual. Kuesioner terdiri dari 30 pertanyaa yang meliputi 5 dimensi kepuasaan. Hasil uji validitas didapatkan hasil $r$ hitung : 0.413-0.779 ( $\mathrm{r}$ tabel $=0.3961)$ dan nilai reliabitias yang telah dilakukan uji validitas dan reliabilitas didapatkan nilai alpha cronbach's 0.948 .

Analisis data dilakukan secara univariat untuk mengetahui gambaran kepuasaan mahasiswa terhadap pembelajaran klinik (preseptorship) dan distribusi di antara masing-masing dimensi kepuasaan. 


\section{HASIL}

Penelitian dilakukan pada bulan Maret-Mei 2018 di salah satu Politeknik Kesehatan di kota Bandung. Jumlah responden adalah 93 orang yang terdiri dari 89 orang perempuan dan 4 orang laki-laki. Rata-rata usia responden adalah 20,56 ( min-mak 20-22) tahun.

Hasil analisis univariat di dapatkan hasil mengenai gambaran tingkat kepuasan mahasiswa DIII Keperawatan seperti tampak pada tabel 1. Tingkat kepuasan pada setiap dimensi dapat dilihat pada tabel 2, bahwa responden lebih banyak puas dibandingkan tidak puas, dari masing-masing dimensi, sebagai berikut: tangible $(54,8 \%)$, reliability $(62,4 \%)$, responsiveness $(66,7 \%)$, assurance $(74,2 \%)$ dan emphaty $(80,6 \%)$.

\section{PEMBAHASAN}

Preceptorship klinis dalam keperawatan adalah program pengajaran dan bimbingan di mana mahasiswa didampingi perawat berpengalaman di lingkungan klinis untuk membekali mereka dengan keterampilan klinis dan nilai-nilai keperawatan (Teferra \& Mengistu, 2017). Program preceptorship meliputi pembelajaran di dalam kelas dan fokus pada peran yang spesifik, dimana komponen yang penting adalah dimana setiap individu mendapatkan bimbingan (Odelius et al., 2017). Preceptorship penting bagi perawat yang baru lulus karena mereka

Tabel 1. Tingkat Kepuasan Mahasiswa DIII Keperawatan dalam Pembelajaran Klinik dengan Metode Preceptorship

\begin{tabular}{ccc}
\hline $\begin{array}{c}\text { Tingkat } \\
\text { Kepuasan }\end{array}$ & Frekuensi & $\begin{array}{c}\text { Presentase } \\
\mathbf{( \% )}\end{array}$ \\
\hline Puas & 49 & 52,7 \\
Tidak Puas & 44 & 47,3 \\
Total & $\mathbf{9 3}$ & $\mathbf{1 0 0}$ \\
\hline
\end{tabular}

berpindah dari mahasiswa menjadi seorang praktisi, yang mana bisa membuat stres bagi para pembimbing. Oleh karena itu Pengaruh persepsi preceptorship membawa aspek positif dan negatif terhadap pendidik (Quek, Ho, Hassan, Quek, \& Shorey, 2019).

Hasil penelitian Omer menyatakan mahasiswa menganggap model preceptorship dengan menggabungkan pendampingan intensif lebih memuaskan daripada model preceptorship peningkatan kemandirian siswa dan pembelajaran mandiri (Omer, Suliman, Thomas, \& Joseph, 2013). Penelitian lain juga menunjukkan hal positif terhadap metode preseptorship yaitu metode ini memiliki pengaruh yang signifikan terhadap peningkatan kompetensi dan sikap mahasiswa karena dapat meningatkan pengalaman dan pengetahuan (Irwin, Bliss, \& Poole, 2018),((Teferra \& Mengistu, 2017).

Tingkat kepuasan antara puas dan tidak puas tidak berbeda secara signifikan. Hal ini dapat dipengaruhi oleh beberapa faktor, menurut Hidayat faktor yang mempengaruhi kepuasan mahasiswa dalam proses belajar mengajar dikaitkan dengan pelaksanaan bimbingan klinik dalam proses pembelajaran diantaranya pertama yaitu persepsi mahasiswa, hal ini meliputi cara pandang mahasiswa terhadap materi yang diberikan baik materi secara langsung maupun materi saat pelaksanaan bimbingan lapangan. Persepsi mahasiswa disini dipengaruhi oleh banyak hal antara lain; pengetahuan, sikap dan

\section{Tabel 2. Tingkat Kepuasan Mahasiswa DIII keperawatan dalam Proses Pembelajaran Klinik berdasarkan Dimensi Kepuasan}

\begin{tabular}{lcccc}
\hline \multirow{2}{*}{$\begin{array}{l}\text { Dimensi } \\
\text { Kepuasan }\end{array}$} & \multicolumn{2}{c}{ Puas } & \multicolumn{2}{c}{ Tidak Puas } \\
\cline { 2 - 5 } Tangible & 51 & 54,8 & 42 & 45,2 \\
Reliability & 58 & 62,4 & 35 & 37,6 \\
Responsiveness & 62 & 66,7 & 31 & 33,3 \\
Assurance & 69 & 74,2 & 24 & 25,8 \\
Emphaty & 75 & 80,6 & 18 & 19,4 \\
\hline
\end{tabular}


motivasi. Kedua profesionalisme dosen/ pendidik, kemampuan pembimbing untuk memberikan bimbingan yang berkualitas, kemampuan atas pengetahuan, keramah-tamahan, kesopanan dan kemampuan komunikasi yang baik. Ketiga adalah akses informasi, kemudahan dalan dalam memperoleh akses informasi yang dibutuhkan oleh mahasiswa berpengaruh pada kepuasan mahasiswa terhadap pelaksanaan proses pembelajaran, informasi memegang peranan penting dalam menunjang kelancaran proses pembelajaran sehingga apa yang menjadi tujuan dan target mahasiswa akan terpenuhi. Keempat sarana dan prasarana yang mendukung proses mengajar mahasiswa maupun yang mendukung proses bimbingan sangat mempengaruhi kepuasan mahasiswa. Sarana dan prasarana yang lengkap serta modern sangat diharapkan agar mahasiswa merasakan kenyamanan dalam proses bimbingan. (Yonge, Myrick, Ferguson, \& Luhanga, 2012).

Selain itu seorang pembimbing klinik juga diharapkan memiliki kompetensi khusus agar dapat memberikan bimbingan yang berkualitas. Abreu \& Interpeler, (2015) menjelaskan kompetensi yang harus dimiliki oleh seorang mentor/ pembimbing klinik yaitu kemampuan intrumental dan kognitif yang baik (berdasarkan evidence based), kompetensi interpersonal (mengembangkan interaksi dengan orang lain), kompetensi sesuai bidang ( patofisiologi, perawatan, sistem informasi teknologi kesehatan dan hal-hal yang berhubungan dengan perawatan)(Abreu \& Interpeler, 2015).

\section{Tingkat Kepuasan Mahasiswa DIII keperawatan dalam Proses Pembelajaran Klinik berdasarkan Dimensi Kepuasan}

\section{Dimensi Tangible}

Hasil penelitian menunjukkan bahwa 51 responden $(54,8 \%)$ puas terhadap aspek tangible (bukti fisik) dan 42 responden (45\%), hal ini menunjukkan pada dimensi ini masih cukup banyak responden yang belum puas dalam aspek fisik. Dimensi tangible merupakan gambaran penampilan fisik dalam pembelajaran klinik, hal ini meliputi gedung (tempat praktik), ruangan, kebersihan, kerapian dan kenyamanan dalam pembelajaran klinik.

Penelitian Supliyani (2014) tentang kepuasaan dalam pencapaian praktik klinik kebidanan menunjukkan terdapat tiga indikator yang perlu perbaikan guna pencapaian kepuasaan mahasiswa yaitu ruangan tempat praktik, peralatan serta perlengkapan yang tersedia dilahan praktik.

Kebutuhan mahasiswa dalam pembelajaran klinik lebih komplek dibandingkan di lingkungan kampus, dimana sebagian peralatan di RS belum dikenal oleh mahasiswa, selain itu peralatan yang tidak sama persis dengan laboratorium, membuat mahasiswa harus beradaptasi terlebih dahulu. Lingkungan RS juga sering menjadi faktor risiko terhadap masalah kesehatan mahasiswa, sehingga diperlukan tindakan preventif untuk mencegah terjadinya risiko kecelakaan maupun penyakit.

\section{Dimensi Reliability}

Tingkat kepuasan dimensi Reliability (kehandalan) di dapatkan kategori puas sebanyak 58 responden. $(62,4 \%)$ dan tidak puas sebanyak 35(37,6\%). Hal tersebut menunjukkan bahwa kehandalan preseptor dalam memberikan pelayanan sesuai dengan tujuan yang telah ditetapkan.

Dalam bimbingan klinik dimensi ini dapat berupa kemampuan dosen atau clinical instructor dalam memberikan bimbingan dalam pelaksanaan praktik klinik keperawatan. Proses bimbingan meliputi diskusi kasus, bed site teaching, informasi tentang penugasan, pemeriksaan target harian, memberikan rekomendasi dari catatan tindak lanjut serta ujian pencapaian kompetensi.

Proses bimbingan sangat mempengaruhi capaian kompetensi mahasiswa. Proses pembelajaran juga berlangsung dua arah karena pembimbing langsung memberikan demonstrasi, pendampingan, pengarahan, dan pelatihan dalam mencapai keterampilan keperawatan yang ingin dicapai(Hamzah, Putri, \& Sumartini, 2019)

\section{Dimensi Responsiveness}

Tingkat kepuasan dimensi responsiveness 
(ketanggapan) didapatkan kategori puas 62 responden $(66,7 \%)$ dan tidak puas 31 responden $(33,3 \%)$. Hal tersebut menunjukkan bahwa dosen telah memberikan pelayanan yang cepat dan tanggap dalam membimbing mahasiswa. Pembimbing klinik diharapkan dapat memberikan pelayanan yang cepat dan berkualitas terhadap kebutuhan dan hambatan yang di alami oleh mahasiswa. Menurut Abreu \& Interpelar (2015) pembimbing klinik yang tanggap terhadap masalah mahasiswa akan memiliki hubungan yang kuat dalam proses bimbingan, sehingga bimbingan klinik yang berkualitas tercapai.

\section{Dimensi Assurance}

Tingkat kepuasan dimensi assurance (ketanggapan) didapatkan kategori puas 69 responden $(74,2 \%)$ dan tidak puas 24 responden $(25,8 \%)$. Dimensi ketanggapan ini di nilai oleh sebagian besar responden dengan katergori puas, hal ini menunjukkan bahwa para pembimbing telah mampu memberikan perhatian, keramahtamahan, kemampuan dalam penyelesaian masalah dalam memberikan pelayanan bimbingan. Dalam bimbingan klinik komponen assurance dapat berupa kemampuan pembimbing klinik untuk memberikan keyakinan bahwa jasa yang diberikannya telah sesuai dengan ketentuan, berkualitas, kemampuan atas pengeathuan, kualitas keramah-tamahan, perhatian dan kesopanan dalam memberikan pelayanan.

Penelitian Supliyani (2014) menunjukkan bahwa priorotas utama untuk dibenahi dalam aspek assurance adalah kemampuan menciptakan lingkungan yang kondusif dan nyaman bagi pembelajaran mahasiswa.

\section{Dimensi Emphaty}

Tingkat kepuasan dimensi responsiveness (ketanggapan) didapatkan kategori puas 75 responden $(80,6 \%)$ dan tidak puas 18 responden $(19,4 \%)$. Kemampuan empati meliputi kemampuan pembimbing klinik memberikan perhatian secara individual meliputi kemudahan mahasiswa memanfaatkan jasa, kemampuan komunikasi untuk menyampaikan informasi yang diperlukan mahasiswa, juga dapat berupa kesediaan pembimbing klinik untuk peduli memberikan perhatian secara pribadi terhadap masalah yang dihadapi.

Penelitian ini menunjukkan bahwa metode Preceptorship mampu memberikan kepuasaan bagi mahasiswa dalam proses pembelajaran klinik, hal ini dapat terjadi tentunya dengan berbagai faktor yang menjadi pendukung dalam pelaksanaannya, seperti sistem bimbingan yang sudah baku dan juga adanya pelatihan preseptorship yang telah di ikuti oleh para pembimbing klinik sehingga dapat memberikan pelayanan dengan baik.

Hasil penelitian Asmara, (2012) tentang implementasi preceptorship pada mahasiswa keperawatan menunjukkan bahwa masingmasing komponen tahu betul tentang peran mereka meskipun ada hambatan selama melakukan metode ini, seperti: jumlah mentor dan pembimbing terbatas, dan jumlah siswa di setiap shift tidak sama. Karena mereka merasa bahwa metode ini efektif, mereka memiliki pemecahan masalah yang akan dilakukan, misalnya: menambahkan jumlah mentor dan pembimbing, menggunakan co-pembimbing untuk membuat jumlah siswa dalam setiap shift sama. Metode ini juga membantu siswa untuk mencapai kompetensi mereka dengan mudah, dan mereka merasa lebih percaya diri selama memberikan asuhan keperawatan kepada pasien.

\section{SIMPULAN}

Hasil penelitian menunjukkan bahwa responden yang menyatakan puas terhadap penggunaan metode Preceptorship yaitu sebanyak 49 orang $(52,7 \%)$ dibandingkan responden yang merasa tidak puas sebanyak 44 orang $(47,3 \%)$. Dari masing-masing dimensi tersebut kategori puas untuk dimensi tangible berjumlah 51 orang $(54,8 \%)$ kemudian kategori puas dimensi reliability sebanyak 58 orang $(62,4 \%)$, selanjutnya kategori puas dimensi responsiveness sebanyak 62 orang $(66,7 \%)$, kemudian untuk dimensi assurance didapatkan hasil puas sebanyak 69 orang $(74,2 \%)$ dan dimensi emphaty $(80,6 \%)$. 


\section{DAFTAR PUSTAKA}

AIPVIKI (2015). Buku kurikulum D III Keperawatan. Jakarta.

Abreu, W. C. de, \& Interpeler, S. S. (2015). Effective Mentorship to Improve Clinical Decision Making and a Positive Identity: A Comparative Study in Turkey and Portugal. International Journal of Information and Education Technology, 5(1), 42-46. https:// doi.org/10.7763/ijiet.2015.v5.473

Asmara, F. Y. (2012). Implementation of mentorship preceptorship method in internship nursing students.

Darmawan, D. (2012). Mentorship dan perceptorship dalam keperawatan. Media Publikasi Penelitian, 66(September), 37-39.

Hamzah, N. N., Putri, S. T., \& Sumartini, S. (2019). the Experience of Nursing Students in the Clinical Learning Using Peer Learning Method. Jurnal Keperawatan Soedirman. https://doi.org/10.20884/1.jks.2019.14.1.790

Health Education England. (2017). Multiprofessional framework for advanced clinical practice in England. Health Education England, 1-23. Retrieved from http:// www.aomrc.org.uk/wp-content/\%0A

Irwin, C., Bliss, J., \& Poole, K. (2018). Does Preceptorship improve confidence and competence in Newly Qualified Nurses: A systematic literature review. Nurse Education Today, 60, 35-46. https://doi.org/10.1016/ j.nedt.2017.09.011

Mukarromah, N. (2016). Hubungan Kompetensi perceptor dalam pelaksanaan program perceptorsip dengan self efficacy ners muda dalam memberikan asuhan keperawatan pada pasien. Health Sciences,

Nursalam, \& Efendi, F. (2008). Pendidikan Dalam Keperawatan Nursalam Ferry Efendi.

Odelius, A., Traynor, M., Mehigan, S., Wasike, M., \& Caldwell, C. (2017). Implementing and assessing the value of nursing preceptorship. Nursing Management, 23(9), 35-37. https://doi.org/10.7748/nm.2017.e1547

Omer, T. Y., Suliman, W. A., Thomas, L., \& Joseph, J. (2013). Perception of nursing students to two models of preceptorship in clinical training. Nurse Education in Practice. $\quad$ https://doi.org/10.1016/ j.nepr.2013.02.003

Quek, G. J. H., Ho, G. H. L., Hassan, N. B., Quek, S. E. H., \& Shorey, S. (2019). Perceptions of preceptorship among newly graduated nurses and preceptors: A descriptive qualitative study. Nurse Education in Practice, 37(May), 62-67. https://doi.org/10.1016/ j.nepr.2019.05.001

Roberts, M. E., Wheeler, K. J., Tyler, D. O., \& Padden, D. L. (2017). Precepting nurse practitioner students: A new view-Results of two national surveys of nurse practitioner preceptors. Journal of the American Association of Nurse Practitioners, 29(8), 484$491 . \quad$ https://doi.org/10.1002/23276924.12482

Supliyani, E. (2014). Kepuasan Mahasiswa Program Studi Kebidanan Bogor dalam Pencapaian Tujuan Pembelajaran Praktik Klinik Kebidanan III di Lahan Praktik. INFOKES, 4(2), 57-71.

Teferra, A. A., \& Mengistu, D. (2017). Knowledge and attitude towards nursing clinical preceptorship among Ethiopian nurse educators: An institution-based crosssectional study. International Journal of $A f$ rica Nursing Sciences, 7(October), 82-88. https://doi.org/10.1016/j.ijans.2017.10.001

Windyastuti, Kristina, T. ., \& Santoso, A. (2016). Pelatihan preceptorship untuk meningkatkan adaptasi perawat baru di rumah sakit. 1-65.

Yonge, O., Myrick, F., Ferguson, L., \& Luhanga, F. (2012). Preceptorship and Mentorship. Nursing Research and Practice, 2012, 1-2. https://doi.org/10.1155 / 2012/790182

Zeithaml, A., \& Berry, L. (1994). Reassessment of Expectations as a Standard in Measuring Comparison Service for Quality: Implications Further Research. Journal of Marketing, 58(1), 111-124. 